\title{
Trinta anos esta noite:busca por segurança e medidas autoritárias na Constituição federal de 1988
}

\author{
Thirty years tonight: search for security and authoritarian measures in the federal \\ Constitution of 1988
}

Treinta años esta noche: búsqueda por la seguridad y medidas autoritarias en la Constitución federal de 1988

Acácio Augusto*

A lei não é a pacificação, pois sob a lei, a guerra continua a fazer estragos no interior de todos os mecanismos de poder.

(Michel Foucault)

\section{Resumo}

Este texto é um breve ensaio que aponta algumas leituras críticas sobre a permanência do elemento autoritário e militar no texto constitucional de 1988. Apresenta situações atuais que demonstram como esse autoritarismo de Estado segue sendo praticado. Afirma a urgência em romper com essa configuração institucional da democracia securitária legada do período ditatorial e recusa a paralisia político-social diante dela.

Palavras-chave: Autoritarismo. Constituição de 1988. Democracia securitária. Segurança pública.

\section{Introdução}

Após trinta anos da promulgação da Constituição federal de 1988, no dia 5 de outubro, o Brasil se encontra em uma escalada autoritária governamental, que dá poucos sinais de recuo: os índices de letalidade estatal, as regulares controvérsias entre os três poderes e o uso extensivo das Forças Arma-

* Doutor em Ciências Sociais (Política) pela Pontifícia Universidade Católica de São Paulo. Professor Adjunto no Departamento de Relações Internacionais da Escola Paulista de Política, Economia e Negócios da Universidade Federal de São Paulo campus Osasco. E-mail: acacioaugusto1980@gmail. com

Recebido em 30/5/2018 - Aprovado em 25/6/2018 http://dx.doi.org/10.5335/hdtv.18n.3.8595 
das para garantia da lei e da ordem atestam esse fato. Como regista o Atlas da violência 2018,

[...] em 2016, o Brasil alcançou a marca histórica de 62.517 homicídios, segundo informações do Ministério da Saúde (MS). Isso equivale a uma taxa de 30,3 mortes para cada 100 mil habitantes, que corresponde a 30 vezes a taxa da Europa. Apenas nos últimos dez anos, 553 mil pessoas perderam suas vidas devido à violência intencional no Brasil (INSTITUTO DE PESQUISA ECONÔMICA APLICADA; FÓRUM BRASILEIRO DE SEGURANÇA PÚBLICA, 2018, p. 3).

A festejada "Constituição cidadã" não foi capaz de criar uma situação político-social que impedisse a propagação da violência que marcou o período de ditadura civil-militar que a antecedeu. Ao contrário, mesmo esvaziada do conteúdo político-ideológico da chamada Guerra Fria, que animava as perseguições de um fantasmagórico inimigo interno, a violência, sobretudo a institucional, só cresceu nesses trinta anos de liberdades constitucionais. Saímos da esperança de "tortura nunca mais", para uma extrema rotinização das violências, sem uma redução significativa do terror de Estado.

De maneira geral, é necessário reconhecer que o papel atribuído pelo liberalismo clássico à lei, a saber, o de conter a tirania governamental, não passa de uma quimera. E isso se dá em todo canto do planeta, pois é sabido o descompasso entre lei e norma, entre o que a lei recomenda ou pretende instituir e sua efetiva operacionalização. Nesse sentido, seria possível argumentar que muito da atual violência autoritária do Estado brasileiro se dá apesar da Constituição de
1988. Mas, ainda assim, não é o caso. Mesmo que reconheçamos a incapacidade da lei em conter a violência dos agentes estatais, os 245 artigos da longa Constituição deixaram portas devidamente abertas para o exercício dessa violência estatal. Umas mais que as outras. A despeito das inéditas garantias de diretos políticos, civis e sociais (nunca efetivados), essa Constituição não marcou o que deveria ter marcado: a derrota das forças que efetivaram e mantiveram o golpe civil-militar de 1964. Se considerarmos, como sugere Michel Foucault (2002), que a lei é sempre um ato de guerra e que, sob ela, a guerra segue sendo travada, a Constituição de 1988 apenas reinscreveu, sob tons mais moderados e com verniz democrático, a guerra que segue sendo travada pelo Estado contra a sociedade no Brasil.

Este breve ensaio pretende apenas apontar alguns episódios atuais dessa guerra e levantar considerações sobre em que ponto ela poderia se inverter. Para isso, retoma leituras críticas sobre a permanência do elemento autoritário e militar no texto constitucional e, em seguida, apresenta situações atuais que demonstram como esse autoritarismo de Estado segue sendo praticado, afirmando, por fim, a urgência em romper com essa configuração institucional, legada do período institucional, e a paralisia político-social diante dela.

Este ensaio se pretende menos como estudo exaustivo da questão e mais como um esboço de diagnóstico do presente, à luz dos trinta anos da peça constitucional, capaz de formular questões urgentes da condição política da cidadania no Brasil. Antecipando o que se diagnostica, do ponto de vista polí- 
tico, é que a atual Constituição brasileira se mostrou uma peça jurídico-política adequada e devidamente elástica para consolidação não de um regime ditatorial aos moldes dos que rodaram o planeta na segunda metade do século $\mathrm{XX}$, mas para a configuração do que venho chamando de democracia securitária, uma prática governamental que não se esgota no texto frio da lei e também se restringe às ações da forma política de governo do Estado.

\section{A permanência do elemento militar na Constituição}

Os últimos acontecimentos no país reascenderam um velho fetiche do cidadão brasileiro médio: a ideia de que os militares seriam uma tábua de salvação do suposto caos social no qual o país mergulhou, ao menos, desde 2016 - ano do fatídico e casuístico processo de impeachment da presidente Dilma Rousseff. Desde então, qualquer mobilização popular que rompa a bolha de grupos politicamente organizados conta com a presença (por vezes folclórica) de grupos que pedem intervenção militar. Tal situação desperta o temor, ou ao menos a dúvida, da possibilidade de volta de um regime ditatorial aos moldes do que vigorou no Brasil entre 1964 e $1985 .{ }^{1}$ Seja de modo minoritário ou não, essas manifestações públicas, que proliferam e se expandem via redes sociais digitais, dão conta que se trata de um desejo em circulação na sociedade brasileira hoje. Mas ele de fato existe? Difícil saber, mas é possível notar o que realmente existe em torno dele e quais as condições jurídico-políticas de sua realização.
Em tese, uma ordem constitucional é instaurada não apenas para findar um período autoritário que a precedeu, mas também para impedir que ele ocorra novamente, fazendo da lei um elemento de contenção da tirania estatal sobre o cidadão. Os exemplos recentes são inúmeros, da Argentina ao Peru, da Espanha à Grécia. Vejamos como isso se dá no Brasil.

Em longo capítulo publicado na coletânea $O$ que resta da ditadura: a exceção brasileira, organizada por Edson Teles e Vladimir Safatle (2010), o politólogo Jorge Zaverucha se dedica a sublinhar a permanência no elemento militar na Constituição de 1988, o que revela, no texto constitucional, o seu legado autoritário. Sua conclusão é, a um só tempo, certeira e aterradora:

A Nova República foi inaugurada sob o pálio militar. Este artigo procurou mostrar que essa proteção ainda se manteve durante os governos FHC e Lula, ora com mais ou menos intensidade, dependendo da conjuntura política (2010, p. 67).

Oito anos após a publicação desse artigo, basta cada um olhar ao seu redor e perceber se algo mudou.

Para chegar a essa conclusão, o artigo descreve como se deu o forte controle militar na redação do texto constitucional condizente à chamada "abertura lenta, gradual e segura". De maneira que a Constituição foi redigida em um ambiente de forte presença militar, assim,

[...] a Carta Magna mudou substancialmente a Constituição autoritária anterior (1967-69). Porém, manteve incólume vários artigos desta Constituição autoritária, referentes às relações civis-militares e policiais (ZAVERUCHA, 2010, p. 67). 
Zaverucha (2010), preocupado com a caracterização formal do regime por meio da análise do texto constitucional e da história das lutas políticas em torno de sua redação, conclui que não apenas o regime que vigora na Nova República é repleto de elementos constitucionais iliberais, ${ }^{2}$ como o que vivemos de fato, desde 1988, é um semidemocracia.

Tais elementos podem ser constatados não apenas no texto constitucional, mas na prática do Judiciário brasileiro e, sobretudo, na maneira como é gerida a política de segurança pública no país, com especial destaque ao sistema carcerário e à atuação das forças policiais. Como mostra Cecília Coimbra (1995), em Guardiões da ordem: uma viagem pelas práticas psi no Brasil do "Milagre", o elemento a ser combatido apenas se metamorfoseou do subversivo para o "delinquente", ambos combatidos como o indivíduo perigoso que ameaça a ordem. Considerando que essa definição de ordem é sempre imprecisa e elástica, é por meio dela, manifesta especialmente nas políticas de segurança (seja interna ou externa), que se instaura o governo ilimitado (OPITZ, 2012).

Voltando ao texto constitucional, essas tendências se manifestam, de forma mais clara, nos artigos $137^{3}$ e $142 .{ }^{4}$ No primeiro, que versa a respeito da declaração do estado de sítio, define-se que, para isso, o presidente deve ter autorização do Congresso nacional. No entanto, considerando as disposições atribuídas às Forças Armadas no artigo 142, conclui-se que o direito soberano de suspensão da lei em nome da garantia da ordem encontra-se de posse das mesmas Forças Armadas. Assim, considerando os fatos dos últimos trinta anos, especialmente aqueles relacionados à segurança pública, os militares saíram do comando do Executivo, mas seguem como atores decisivos na política nacional.

Como conclui Zaverucha,

[...] em síntese, os militares brasileiros continuam a exercer influência política e detêm prerrogativas incompatíveis com um regime democrático. Esta influência vem aumentando, na aérea da 'lei e da ordem', especialmente, com as sucessivas greves das Polícias Militares estaduais e com o aumento do narcotráfico. A visão militar tende a analisar questões de segurança pública sob as lentes da segurança nacional (2010, p. 75).

Chegamos em 2018 e não apenas essa situação se agudizou, como se encontra em um preocupante ponto de inflexão. A presença dos milhares na política e na vida pública nacional (pensem na profusão de generais regularmente se manifestando em redes sociais digitais) apenas aumenta, e sua presença no Poder Executivo é menos indireta. A começar pelo Ministério da Defesa, criado em 1999, com intensão de dar um verniz de controle civil aos miliares, hoje é ocupado por um militar, o general de Exército da reserva Joaquim Silva e Luna; ${ }^{5} \mathrm{o}$ Gabinete de Segurança Institucional, desde sempre ocupado por militares, tem hoje um ministro extremante ativo, o general Sérgio Etchegoyen; ${ }^{6}$ por fim, a criação recente de um Ministério Extraordinário da Segurança Pública, que, apesar de ser ocupado pelo civil Raul Jungmann, tem como seu principal instrumento o acionamento das Forças Armadas para assuntos de segurança pública. E, para edulcorar essa situação, recorrendo 
mais uma vez aos artifícios autoritários da Constituição federal de 1988, um dos principais estados da federação, o Rio de Janeiro, está sob intervenção militar.

De maneira que, além da conformação legal e da classificação teórico-formal dos regimes, o Brasil, hoje, não é nem uma democracia, nem uma ditadura. Também os elementos iliberais da Constituição não parecem suficientemente descritivos da situação, na medida em que sempre estiveram presentes. Assim, diante dessa zona de indistinção entre o não mais ser uma democracia e o ainda não ser uma ditadura, estamos vivendo em uma democracia securitária plenamente constitucional.

\section{Acrise como modo de governo da democracia securitária}

A intervenção constitucional e militarizada na pasta de Segurança Pública do estado do Rio de Janeiro, instituída por decreto presidencial e capitaneada por um general das Forças Armadas Brasileiras, o general do Exército Walter Souza Braga Netto, acontece em um momento em que a configuração de uma democracia securitária fica escancarada. Algo tão absurdo e, a um só tempo, tão possível, que as reações são de paralisia, compasso de espera, pedidos de explicação, até finalmente chegar à resignação e à normalização da situação. E isso se dá a despeito das regulares notícias de insucesso da empreitada e abafamento das manifestações dos que são diretamente atingidos pela violência estatal.
Tal decisão governamental é inédita e está inserida num fluxo que ninguém sabe ao certo em que ponto começou a escorrer. Um marco é a Garantia de Lei de Ordem (GLO) de 1992, para garantir a realização da ECO-92 na cidade do Rio de Janeiro. Então, após os pronunciamentos protocolares das autoridades, segue-se a enxurrada de explicações, análises, comentários e opiniões de especialistas, ou não, que se perdem na algaravia das coisas ditas e escritas nas telas de computadores pessoais, celulares inteligentes e televisores de tela plana, como se a Terra fosse mesmo plana. Isso ocorre porque tudo se passa como se não fosse o fim último, e, ao mesmo tempo, ainda não é o começo de nada.

Essa intervenção confirma uma série de tendências autoritárias das democracias que já vinham se firmando, mas, ao mesmo tempo, aponta para os próximos passos. Curioso é notar como ela contradiz as teses sobre o estado de exceção (em sentido vulgar), pois mostra como é o funcionamento mesmo da democracia hoje, na qual se combina saneamento monetário (que é falso, pois no fundo é realocação de recursos e continuidade do roubo regular dos que se locupletam com erário público) com endurecimento do confronto, repressão, controles eletrônicos. A esta combinação dá-se o nome de política de austeridade (as semelhanças com a Grécia são evidentes, especialmente no estado do Rio de Janeiro). Estamos, com isso, enredados num processo de desconstrução do que conhecemos como democracia - undoing the demos, como diz Wendy Brown (2015) -, ou isso é apenas o esgarçamento dessa ilusória 
promessa de isonomia e isegoria que nos fez a democracia moderna?

O certo é que as crises não provocam mais momentos de ruptura, tornando-se o modo mesmo de governar os vivos. E, justamente por isso, esses vivos desejam mais e mais segurança. De modo que, hoje, ao invés de grandes golpes que mudam os rumos da configuração do Estado e da democracia, assistimos aos regulares dispositivos de exceção, próprios das democracias modernas, serem acionados a todo tempo em nome da segurança. Assim, temos o que podemos nomear de uma democracia securitária, para qual a justiça criminal e as Forças Armadas cumprem papel central. Isso explica, de um lado, a extrema militarização das polícias e, de outro, a policialização dos exércitos. Entre uma e outra, o resultado é a transformação dos espaços urbanos em praças de guerra e o aumento vertiginoso da letalidade estatal. No Brasil, isso se traduz em algo como 60 mil cadáveres empilhados todo ano, quase todos pretos e pobres. Se nos anos 1990 cantava-se que "o Haiti é aqui", hoje o número de mortes ultrapassa o acúmulo de cadáveres no conflito da Síria.

Neste quadro, a justiça criminal se amplia e se "democratiza", tornando-se o locus das decisões políticas em todos os âmbitos (do local-pessoal ao nacional-internacional), uma consolidação da judicialização da vida, que definitivamente se torna vetor e forma da vida pública e biológica dos viventes. Ao mesmo tempo, as Forças Armadas redefinem suas funções, adequando-se sempre que possível às regras constitucionais e aos protocolos das organizações internacionais, atuando em novos espaços e elegendo novos objetivos estratégicos, para os quais o cidadão fica entre ser o objeto de proteção (vulnerável), de um lado, e virtual inimigo a ser eliminado (ora terrorista, ora traficante, ora black bloc, ora corrupto, enfim, produtor de vulnerabilidades), de outro. Tal estado das coisas expõe as novas construções do inimigo social e confere novo sentido à máxima "é preciso defender a sociedade".

Governar tornou-se a principal tecnologia de poder moderno para além de suas formas institucionais, pois se trata da prática de governo de todos por todos, muito ao modo do que Michel Foucault chamou de governamentalidade:

[...] o conjunto constituído pelas instituições, procedimentos, análises e reflexões, os cálculos e as táticas que permitem exercer essa forma bem específica, ainda que complexa, de poder que tem por alvo principal a população, por forma maior de saber a economia política e por instrumento técnico essencial os dispositivos de segurança $(2008$, p. 143-144).

Tecnologia de governo dos vivos que não abre mão do racismo de Estado, seu argumento definitivo para matar, executar. Evidente que chegamos a um ponto agudo disso tudo com intervenção militar, mas como o poço não tem fundo, a execução da vereadora do PSOL, Marielle Franco, no dia 14 de março de 2018, mostra-se um ponto de clivagem radical desse quadro. Ultrapassa todos os limites da rotinizada violência letal dessa democracia securitária; coloca para cada um a urgência em assumir um lado nessa guerra estúpida. A aparente oposição entre milícias parapoliciais/paramilitares e as forças da intervenção militar é fumaça que turva essa tomada de posição. As especulações 
sobre os usos eleitorais disso, mesmo que em parte verdadeiras, só servem para preencher os inócuos debates televisivos e jornalísticos feitos pelos esbranquiçados especialistas. É preciso saber, de forma inequívoca, que quem executou Marielle Franco foi o Estado. E, por exercício de lógica formal, constatar que os mandantes da execução são os mandatários do governo e capitães da intervenção federal militarizada.

Embora a dominância policial, que extravasa lei e direito por natureza da função, seja uma constatação perene a respeito da sociabilidade autoritária e da vida sob a dominância estatal moderna, nos últimos tempos há uma cidadania policial que se amplifica no Brasil. Esta ampliação das condutas policiais também repercute institucionalmente, produzindo maior empoderamento e legitimação social das polícias propriamente ditas, como a Militar, a Civil e a Federal. E, nisso, temos o acionamento regular das Forças Armadas para atuarem como força de polícia, na condição de destacamento especial para emprego legitimado da violência pelo Estado. Note-se que, no Brasil, a partir da Operação Rio (1994-1995), o acionamento das Forças Armadas Brasileiras, em especial o Exército, por meio da GLO, ${ }^{7}$ foi perdendo o caráter de excepcionalidade. Tomando como exemplo eventos recentes, como a pacificação das favelas no Rio de Janeiro e as chamadas crises da segurança pública no norte do país, Espírito Santo e Goiás, pode-se dizer que o papel orgânico de força auxiliar de reserva do Exército Brasileiro, atribuído às polícias militares dos estados, foi invertido, tornando as Forças Aramadas quase que destacamentos auxiliares dos governadores, ainda que o comando do exército declare, regularmente, não gostar nada disso.

A constatação analítica de Paulo Arantes, em seu ensaio sobre as jornadas de junho de 2013, passados quase cinco anos, é confirmada: "Depois de junho a paz será total" (2014, p. 452). A reação conservadora, no sentido literal da palavra, já que ela não foi apenas do Estado e tampouco ficou restrita aos setores ideologicamente identificados como conservadores e/ou de direita, intensificou-se conforme a aproximação, pós-junho 2013, dos chamados megaeventos (Copa do Mundo 2014 e Olimpíadas Rio 2016) e, antes destes, Rio+20 e visita do Papa Francisco (Jornadas da Juventude), repercutindo fortemente em ajustes e reformas institucionais, especialmente no que se refere ao campo da segurança (interna e/ou externa, se é que essas divisões ainda fazem, hoje, algum sentido no plano das práticas). Algo que fica explícito na reconfiguração das polícias: novos equipamentos e treinamentos especiais ministrados pelas Forças Armadas e em parceria com as polícias da Inglaterra e da França; criação de novos batalhões especiais de polícia e emissão regular de GLOs; promulgação de uma nova lei antiterrorismo (Lei n ${ }^{\circ} 13.260$, de 16 de março de 2016); maior atenção das forças policiais em registar em vídeo as operações, assim como monitorar as redes sociais digitais.

É evidente que tudo isso já estava em andamento muito antes de 2013, a Força Nacional de Segurança, por exemplo, foi criada em 2006. Mas "depois de junho", a figura, meio fantasmagórica, de um inimigo difuso e sem rosto (ou de rosto coberto) paradoxalmente tomou contornos mais discerní- 
veis, ou o discurso do medo da desordem se tornou mais palpável para as pessoas, a partir de casos pontuais, como a morte do cinegrafista Santiago Andrade durante uma manifestação no Rio de Janeiro. Algo que, presumivelmente, os alvos seletivamente regulares das forças de segurança mais expostos à violência e/ou, no jargão de dominância liberal, aos abusos de autoridade já sentiam pesar sobre eles muito antes disso. $\mathrm{O}$ caso de Amarildo, que foi morto sob tortura em uma Unidade de Polícia Pacificadora (UPP) e dado como desaparecido, foi um alerta sobre esse avanço, que não encontrou eco. O caso de Rafael Braga Vieira, preso em junho de 2013 no Rio de Janeiro, condensa bem essa reconfiguração de continuidade e ampliação das forças de segurança sobre a população civil que se faz de forma difusa e capilar. E, agora, Marielle Franco.

Em São Paulo, as coisas não são muito diferentes, mas na capital bandeirante dispensa-se o auxílio das armadas por possuírem uma polícia que, na verdade, é um verdadeiro exército. Basta reparar na violência brutal ao final dos atos do Movimento Passe Livre (MPL), como no dia 11 de janeiro de 2018. Ela foi obra dos soldados integrantes de uma companhia da polícia chamada Batalhão de Ações Especiais de Polícia (Baep). Ao todo, foram mobilizados, naquele dia, segundo a Polícia Militar do Estado de São Paulo (PMESP), 400 policiais para o ato, nem todos do Baep. Mas, se considerarmos que, também segundo a Polícia Militar, estavam presentes no ato cerca 1.500 manifestantes (MPL falou de 10 a 20 mil), conclui-se que, na conta da polícia, em operações como esta, é necessário quase um policial para cada 3 pessoas, uma proporção absurda. Se considerarmos o contingente de Guardas Civis Metropolitanos mobilizados para o evento e demais agentes que talvez não entrem nas contas oficiais, isso se torna ainda mais absurdo.

O primeiro desses batalhões especiais da PMESP foi criado em 6 de janeiro de 2014, com sede na cidade de Campinas, por força do Decreto $n^{\circ}$ 60.034, que complementou o Decreto ${ }^{\circ} 55.742$, de 27 de abril de 2010. Desde então, foram criados mais cinco batalhões especiais. $\mathrm{O}$ artigo $2^{\circ}$ do decreto de 2014 determina que o Baep é

[...] responsável pelas seguintes atividades: I - execução de: a) operações especiais de polícia ostensiva e de preservação da ordem pública; b) ações de controle de distúrbios civis e de antiterrorismo (SÃO PAULO, 2014, não paginado, grifo nosso).

A data e o texto do decreto deixam clara a vinculação com a expansão das ações de pacificação e processos de securitização militarizada do espaço urbano no pós-2013. A capital bandeirante, com seu pioneirismo, já tem sua democracia securitária muito bem organizada.

$\mathrm{O}$ exposto até o momento, portanto, mostra a centralidade da segurança na vida contemporânea. Não é necessário ir muito longe para perceber que hoje, em nome da segurança, é possível justificar quase tudo. A vida regular é repleta de pequenas humilhações, as quais somos submetidos para garantir a segurança de si e dos outros. Essas humilhações e violências são ainda priores contra os pretos, os pobres, as mulheres e as subjetividades anômalas. Não é coincidência que Marielle Franco seja um pouco 
de cada uma. Assim, as suspeições regulares que caem sobre os sujeitos ampliam-se, tornando a todos e a qualquer um possíveis ameaças à ordem e/ou virtuais terroristas, ou seja, alvos do terrorismo de Estado. Isso se tornou tão naturalizado que aquele que arrisca questionar é tomado como louco e visto, imediatamente, como uma pessoa suspeita, a ser escrutinada pelas forças da ordem ou submetida aos dispositivos de monitoramento. No limite dessa prática de governo está o racismo de Estado que executou Marielle, sumiu com Amarildo e mantém preso Rafael Braga.

No entanto, quando mobilizações específicas como a luta contra a tarifa ou contra o extermínio de pretos e pobres pela polícia entram em cena, a ação das forças da ordem torna-se especialmente escandalosa e notadamente explícita. Em nome da manutenção da ordem, da defesa do patrimônio (estatal e/ou privado) e até da segurança dos próprios manifestantes (sic), qualquer ação, mesmo que extremamente violenta, justifica-se. Mesmo que ela seja uma execução extrajudicial e paragovernamental. E não existe princípio democrático, direitos civis ou humanos, nem mesmo garantia da integridade física das pessoas, que sejam capazes de frear a mobilização violenta das forças de segurança e seu emprego espetacular contra os cidadãos, muitas vezes de forma letal. Mesmo a questão da legitimidade do emprego dessa violência, tão cara ao pensamento liberal e aos defensores dos direitos constitucionais, torna-se secundária. Não é à toa que a relação entre força violenta de polícia e lei é, até hoje, o nó cego do direito administrativo. E, mesmo que haja preocupação (ao menos teórica e retórica) em desfazer esse nó, os acontecimentos recentes (cada vez mais traumáticos e agudos) mostram que questionamentos sobre isso, quando são feitos, tornam-se quase que protocolares ou hipocritamente contingenciais e freados por malabarismos hermenêuticos das autoridades, especialmente as ligadas ao Poder Judiciário, ou diluídos em pautas genéricas dadas pela grande imprensa e pelas redes sociais digitais. Nesse sentido que é possível afirmar que estamos num momento de consolidação de uma democracia securitária, e não que estejamos em um estado de exceção permanente ou a caminho de uma ditadura, ao estilo das que governaram durante quase todo o século XX, especialmente em nuestra america.

Entramos, em 2018, em ano de eleições majoritárias para os poderes executivos e legislativos em todo o Brasil. Eleições já iniciadas muito antes de sua partida oficial e com configurações e contingências nada convencionais. Um processo eleitoral eivado de medos, suspeitas, ameaças, hostilidades e, como gostam de falar os juristas e institucionalistas, com sérios riscos de insegurança jurídica e constitucional. Isso já era verdade antes da execução brutal de Marielle Franco, hoje, isso é um truísmo. Seria "natural" que um movimento social mostrasse alguma relação e algum interesse por essa disputa de cadeiras e cargos, para evitar o vazio jargão "disputa de narrativas". No entanto, ao insistir em suas pautas específicas, lutas pontuais, irritando e provocando suspeita de ambos os lados que vivem em função da disputa pelo centro, algo mais decisivo e urgente se torna explícito: a exposição de que 
quem governa não está interessado em cessar o banho de sangue e que polícia e exército são os principais agentes da violência que os governantes dizem combater.

Isso é possível precisamente porque a insistência com a pauta específica leva o movimento a não caminhar em direção ao palco do espetáculo do Poder Executivo, com suas novas e velhas (emergentes e decadentes) celebridades; a não buscar cadeiras no balcão de negociações do Poder Legislativo, seja entre os mais mesquinhos ou entre os mais filantropos dos seus negociadores. É preciso ocupar as ruas, como fizeram as mulheres negras e seus tambores após a execução de uma delas, e que não se perca de vista que Marielle é uma delas. Essa decisão de ocupar as ruas e fazer desta a arena e o instrumento da luta faz com que esta verdade, no mínimo inconveniente, emerja: é preciso desativar o disposto genocida do racismo de Estado. Pois, se os ocupantes do governo se alternam, a polícia militarizada e o exército cumprindo o papel de polícia ficam. Algo que se dá a despeito das estrelas decadentes ou ascendentes que ocupam e se ocupam da política de governo.

Se o Estado é lugar da política moderna, no qual todos buscam reconhecimento, é preciso acontecer uma revolta antipolítica nas ruas. Para que isso se produza, pouco importa se, nas ruas, estão cem ou um milhão de pessoas, pouco importa se, nas redes sociais digitais, isso receba um ou mil likes, pois o que provoca o incômodo e tem a potência de expor o escândalo da verdade dos governos é a coragem de ser minoria.

Como disse o artista Rogério Duarte, ao relatar sua experiência de tortura durante a ditadura civil-militar no Brasil (1964-1985), momento em que esteve diante d'A Grande Porta do Medo: " [...] pode ser que exista um princípio e um fim para as estórias, mas o que de fato interessa é o rio de sangue que corre no meio" (2003, p. 27).

\section{Abstract}

A brief essay that points out some critical readings about the permanence of the authoritarian and military element in the constitutional text of 1988. It presents current situations that demonstrate how this authoritarianism of State continues being practiced. It affirms the urgency to break with this institutional configuration of the securary democracy bequeathed of the dictatorial period and refuses the political-social paralysis before it.

Keywords: Authoritarianism. 1988 Constitution. Security democracy. Public security.

\section{Resumen}

Breve ensayo que apunta algunas lecturas críticas sobre la permanencia del elemento autoritario y militar en el texto constitucional de 1988. Presenta situaciones actuales que demuestran cómo ese autoritarismo de Estado sigue siendo practicado. Afirma la urgencia en romper con esa configuración institucional de la democracia securitaria legada del período dictatorial y rechaza la parálisis político-social ante ella.

Palabras clave: Autoritarismo. Constitución de 1988. Democracia securitaria. Seguridad pública. 


\section{Notas}

1 Como dito, tal situação já era visível nas manifestações a favor do impeachment da presidente Dilma Rousseff, mas, para ficar num evento recente, isso apareceu novamente na greve dos caminhoneiros em maio de 2018. Cf. "Em grupos no WhatsApp, caminhoneiros pedem intervenção militar". Disponível em: <https://istoe.com. $\mathrm{br} /$ em-grupos-do-whatsapp-caminhoneiros-pedem-intervencao-militar/>. Acesso em: $27 \mathrm{abr}$. 2018.

2 Sobre essa caracterização dos governos atuais, em todo o planeta, que na busca por segurança constituem-se como governos ilimitados ou não liberais (unliberal, no inglês), ver Opitz (2012), que utiliza a analítica foucaultiana, partindo de referências diferentes das de Zaverucha, mas chega a conclusões muito aproximadas.

3 Art. 137. O Presidente da República pode, ouvidos o Conselho da República e o Conselho de Defesa Nacional, solicitar ao Congresso Nacional autorização para decretar o estado de sítio nos casos de: I - comoção grave de repercussão nacional ou ocorrência de fatos que comprovem a ineficácia de medida tomada durante o estado de defesa; II - declaração de estado de guerra ou resposta a agressão armada estrangeira (BRASIL, 1988).

4 Art. 142. As Forças Armadas, constituídas pela Marinha, pelo Exército e pela Aeronáutica, são instituições nacionais permanentes e regulares, organizadas com base na hierarquia e na disciplina, sob a autoridade suprema do Presidente da República, e destinam-se à defesa da Pátria, à garantia dos poderes constitucionais e, por iniciativa de qualquer destes, da lei e da ordem (BRASIL, 1988).

5 Conferir site do Ministério da Defesa. Disponível em: <https://www.defesa.gov.br/ministro-da-defesa>. Acesso em: 27 abr. 2018.

6 Conferir site do Gabinete de Segurança Institucional da Presidência da República. Disponível em: <http://www.gsi.gov.br/>. Acesso em: 27 abr. 2018.

7 As GLOs são realizadas exclusivamente por ordem expressa da Presidência da República para convocar a intervenção das Forças Armadas em situações nas quais se avalia que houve esgotamento da capacidade das forças de segurança pública em garantir a ordem política e social (Cf. Art. 144, da Constituição de 1988). Juridicamente, a GLO é disciplinada pelo artigo 142 da Constituição federal de 1988 e regulada pela
Lei Complementar n ${ }^{\circ}$ 97/1999 e pelo Decreto $n^{\circ}$ $3.897 / 2001$, que "fixa as diretrizes para o emprego das Forças Armadas na garantia da lei e da ordem, e dá outras providências". No início de 2014, assessores civis e militares, atendendo a uma solicitação do Ministério da Defesa, produziram um "Manual de GLO", que padroniza a rotina e serve de orientação doutrinária para as forças destacadas para este tipo de atividade exclusiva das Forças Armadas.

\section{Referências}

ARANTES, Paulo. O Novo Tempo do Mundo e outros estudos sobre a era da emergência. São Paulo: Boitempo, 2014.

BRASIL. Constituição (1988). Constituição da República Federativa do Brasil: promulgada em 5 de outubro de 1988. Brasília, DF, 1988. Disponível em: <http://www.planalto.gov. br/ccivil_03/constituicao/constituicaocompilado.htm>. Acesso em: 10 maio 2018.

BRASIL. Decreto $\mathrm{n}^{\circ}$ 3.897, de 24 de agosto de 2001. Brasília, DF, 2001. Disponível em: <http://www.planalto.gov.br/cciViL_03/decreto/2001/D3897.htm>. Acesso em: 21 maio 2018 .

BROWN, Wendy. Undoing the demos: neoliberalism's stealth revolution. New York: Zone Books, 2015

COIMBRA, Cecília Maria Bouças. Guardiões da ordem: uma viagem pelas práticas psi no Brasil do "Milagre". Rio de Janeiro: Oficina do Autor, 1995.

DUARTE, Rogério. A grande porta do medo. In: Tropicaos. Rio de Janeiro: Beco do Azougue, 2003. p. 25-48.

FOUCAULT, Michel. Em defesa da sociedade. São Paulo: Martins Fontes, 2002.

Segurança, território, população. São Paulo: Martins Fontes, 2008.

INSTITUTO DE PESQUISA ECONÔMICA APLICADA; FÓRUM BRASILEIRO DE SE- 
GURANÇA PÚBLICA. Atlas da violência 2018. Rio de Janeiro: IPEA/FBSP, 2018. Disponível em: <http://www.ipea.gov.br/portal/index. php?option $=$ com_content\&view $=$ article\&i$\mathrm{d}=33410 \&$ Itemid=432>. Acesso em: 20 maio 2018.

OPITZ, Sven. Governo não ilimitado - o dispositivo de segurança da governamentalidade não-liberal. Ecopolítica, São Paulo, n. 2, p. 3-36, 2012.

SÃO PAULO. Decreto $n^{\circ}$ 60.034, de 06 de janeiro de 2014. São Paulo, SP, 2014. Disponível em: <https://www.al.sp.gov.br/norma/172178>. Acesso em: 15 maio 2018.

ZAVERUCHA, Jorge. Relações civil-militares: o legado autoritário da Constituição brasileira de 1988. In: TELES, Edson; SAFATLE, Vladimir (Org.). O que resta da ditadura. São Paulo: Boitempo, 2010. p. 102-138. 